\title{
PALEOCANAIS NA PLATAFORMA CONTINENTAL INTERNA DO RIO GRANDE DO SUL: EVIDÊNCIAS DE UMA DRENAGEM FLUVIAL PRETÉRITA
}

\author{
José Gustavo Natorf de Abreu e Lauro Júlio Calliari² \\ Recebido em 28 janeiro, 2005 / Aceito em 5 outubro, 2005 \\ Received on January 28, 2005 / Accepted on October 5, 2005
}

\begin{abstract}
Subsurface structures mapped by the Sparker B) acoustic system on the inner continental shelf of Rio Grande do Sul State, in southern Brazil were interpreted as paleochannels which developed over a coastal plain environment during the upper Pleistocene and lower Holocene. Two major reflectors displaying expressive lateral continuity were identified. The first reflector, which is shallower, is buried at depths ranging from 10 to $12 \mathrm{~m}$ and its surface is relatively homogeneous displaying few irregularities associated that channeled structures. The second reflector mapped on depths ranging from $14 \mathrm{a} 32 \mathrm{~m}$ is more discontinuous and irregular and display erosive structures. The overall interpretation of the shallow seismic reflection profiles indicates that this preterit drainage display an N/NE-SE/SW orientation increasing its width and decreasing its depth towards offshore. The presence of paleochannels in the inner continental shelf of RS state supports the paleogeographic models of the area proposed by early studies.
\end{abstract}

Keywords: Seismic survey, Inner continental shelf, Rio Grande do Sul State.

RESUMO. Estruturas subsuperficiais da plataforma continental interna do Rio Grande do Sul (RS), no sul do Brasil, registradas através do sistema acústico SparkerßB), foram interpretadas como paleocanais, que se desenvolveram sobre um ambiente de planície costeira, anterior à transgressão ocorrida no final do Pleistoceno e início do Holoceno. Dois refletores principais, com expressiva continuidade lateral, foram identificados. 0 primeiro refletor, mais raso, situa-se entre $10 \mathrm{~m}$ e $12 \mathrm{~m}$ em subsuperfície e se caracteriza como uma superfície bastante homogênea, com algumas irregularidades localizadas, de dimensões reduzidas, próximas a feições acanaladas. 0 segundo refletor, localizado a profundidades que variam entre $14 \mathrm{~m}$ e $32 \mathrm{~m}$, em relação ao fundo marinho, é mais descontínuo e sua superfície mais irregular, com a presença de estruturas erosivas. A análise conjunta dos perfis indica que esta drenagem pretérita apresenta uma orientação N/NE-SE/SO, reduzindo sua profundidade e aumentando sua largura em direção ao mar aberto. A presença de paleocanais na plataforma interna do Rio Grande do Sul reforça os modelos de evolução paleogeográfica da área, conforme propõe os estudos realizados anteriormente.

Palavras-chave: Levantamentos sísmicos, Plataforma Continental Interna, Rio Grande do Sul.

\footnotetext{
${ }^{1}$ Laboratório de Oceanografia Geológica (LOG), Centro de Ciências Tecnológicas da Terra e do Mar (CTTMar), Universidade do Vale do Itajaí (UNIVALI), Rua Uruguai, 458, Centro, Itajaí, Santa Catarina, CEP: 88302-202, CP. 360; Telefone: (047)-341-7718; Fax: (047)-341-7715 - E-mail: gabreu@univali.br

${ }^{2}$ Laboratório de Oceanografia Geológica (LOG), Departamento de Geologia (DEGEO), Fundação Universidade Federal do Rio Grande (UFRG), Av. Itália Km 9 , Rio Grande (RS), CEP: 96201-900, CP. 474; Telefone: (053)2336518 - E-mail: tsclauro@furg.br
} 


\section{INTRODUÇÃO}

Registros sísmicos que comprovam a existência de drenagens pretéritas, através de paleocanais subsuperficiais na plataforma continental interna do Rio Grande do Sul são escassos, em decorrência da reduzida densidade de informações de caráter geofísico nesta área da plataforma sul-brasileira.

Durante a Operação Geocosta Sul I, realizada pelo Laboratório de Oceanografia Geológica da Fundação Universidade Federal do Rio Grande (LOG/FURG), nas proximidades da desembocadura da lagoa dos Patos, em 1983, foram coletadas amostras superficiais que indicaram a presença de um depósito arenoso terrígeno, típico de um ambiente fluvial (Calliari, 1984). As características texturais e mineralógicas sugeriram a hipótese da existência de paleocanais, retrabalhados pela dinâmica da plataforma continental, expondo e dispersando os sedimentos continentais por sobre a sua superfície. Mais tarde, a Operação Geocosta Sul II, realizada em abril de 1984, na mesma área, e empregando o método sísmico raso Sparker $\circledast$, registrou a presença de estruturas que foram interpretadas como canais fluviais soterrados pelo prisma sedimentar da atual plataforma interna. Estes registros vieram corroborar a hipótese da existência de uma drenagem pretérita, desenvolvida em período de nível do mar baixo, estendendo-se sobre uma planície costeira extensa e posteriormente soterrada pela sedimentação arenosa transgressiva.

0 propósito deste trabalho é descrever as características dos refletores mapeados durante esta operação, os quais estão relacionados a processos sedimentares pretéritos, contribuindo desta forma, com os modelos evolutivos propostos para a plataforma continental por Corrêa (1982), Corrêa \& Ade (1987), Corrêa et al. (1996), Martins et al. (1996), bem como, para os trabalhos de Villwock (1984), Villwock et al. (1986), Villwock \& Tomazelli (1995) e Tomazelli et al. (2000) para a planície costeira do Rio Grande do Sul.

\section{ÁREA DE ESTUDO Localização}

A área de trabalho localiza-se na plataforma continental interna do Rio Grande do Sul entre as latitudes $31^{\circ} 30^{\prime}$ S e $32^{\circ} 30^{\prime} \mathrm{S}$ e as longitudes $51^{\circ} 00^{\prime} 0$ e $51^{\circ} 30^{\prime} 0$, estendendo-se desde a localidade de Mostardas até a desembocadura da lagoa dos Patos, na cidade de Rio Grande (Fig. 1).

\section{Geomorfologia da Plataforma Continental Interna}

Nesta região o relevo da plataforma continental apresenta duas porções bem distintas, sendo a desembocadura da lagoa dos Pa- tos a região de transição dos padrões morfológicos e sedimentares da plataforma. Ao sul da desembocadura, o fundo submarino é extremamente homogêneo e sem irregularidades notáveis no seu relevo (Calliari \& Abreu, 1984, Calliari \& Fachin, 1993 e Calliari et al., 1994). Em contraste, ao norte da barra, a plataforma apresenta a ocorrência de bancos arenosos lineares que chegam a apresentar diferenças de até $5 \mathrm{~m}$ entre a crista e a cava e comprimentos que podem atingir até 18 milhas náuticas (Figueiredo Jr., 1975). Neste setor, Calliari \& Abreu (1984), mapearam um conjunto de três elevações, situadas aproximadamente a 16MN a leste da barra da lagoa dos Patos, que constituem os únicos substratos naturais consolidados existentes na região. 0 conjunto destas elevações, conhecido como parcel do Carpinteiro, se constitui em um afloramento de "beach rocks" que, segundo Figueiredo Jr. (1980), pode estar relacionado à antiga linha de praia, em períodos de regressão marinha.

As flutuações do nível relativo do mar também deixaram marcas na plataforma continental. Corrêa \& Ade (1987), Corrêa et al. (1996), Corrêa \& Toldo Jr. (2002) assinalam a presença de escarpas erosivas situadas a diferentes profundidades as quais os autores associaram às estabilizações ocorridas durante a transgressão subseqüente ao Último Máximo Glacial.

\section{Sedimentologia}

A sedimentologia da plataforma interna adjacente ao Estado do Rio Grande do Sul é amplamente dominada pela fácies arenosa, constituída de areias quartzosas médias a finas, de características muito similares às atuais areias de praia e dunas da planície costeira (Martins et al., 1972; Corrêa et al., 1996). A cobertura arenosa é interrompida na altura da barra da lagoa dos Patos pelos sedimentos síltico-argilosos da fácies Patos (Martins et al., 1972; Kowsmann, 1973; Calliari \& Fachin, 1993), provenientes do sistema lagunar Patos-Mirim e depositados por floculação em sua desembocadura (Calliari \& Fachin, 1993).

Depósitos de cascalho biodetrítico também ocorrem em acumulações esparsas, modificando o padrão arenoso da plataforma interna. A fácies biodetrítica se distribui pela área situada entre o farol da Conceição e o farol Sarita, depositando-se nas cavas dos bancos arenosos que se desenvolvem nesta região (Calliari \& Abreu, 1984). Esta mesma relação morfogenética já havia sido citada por Figueiredo Jr. \& Kowsmann (1976) quando estudaram os bancos da região do Albardão, localizados mais a sul. 


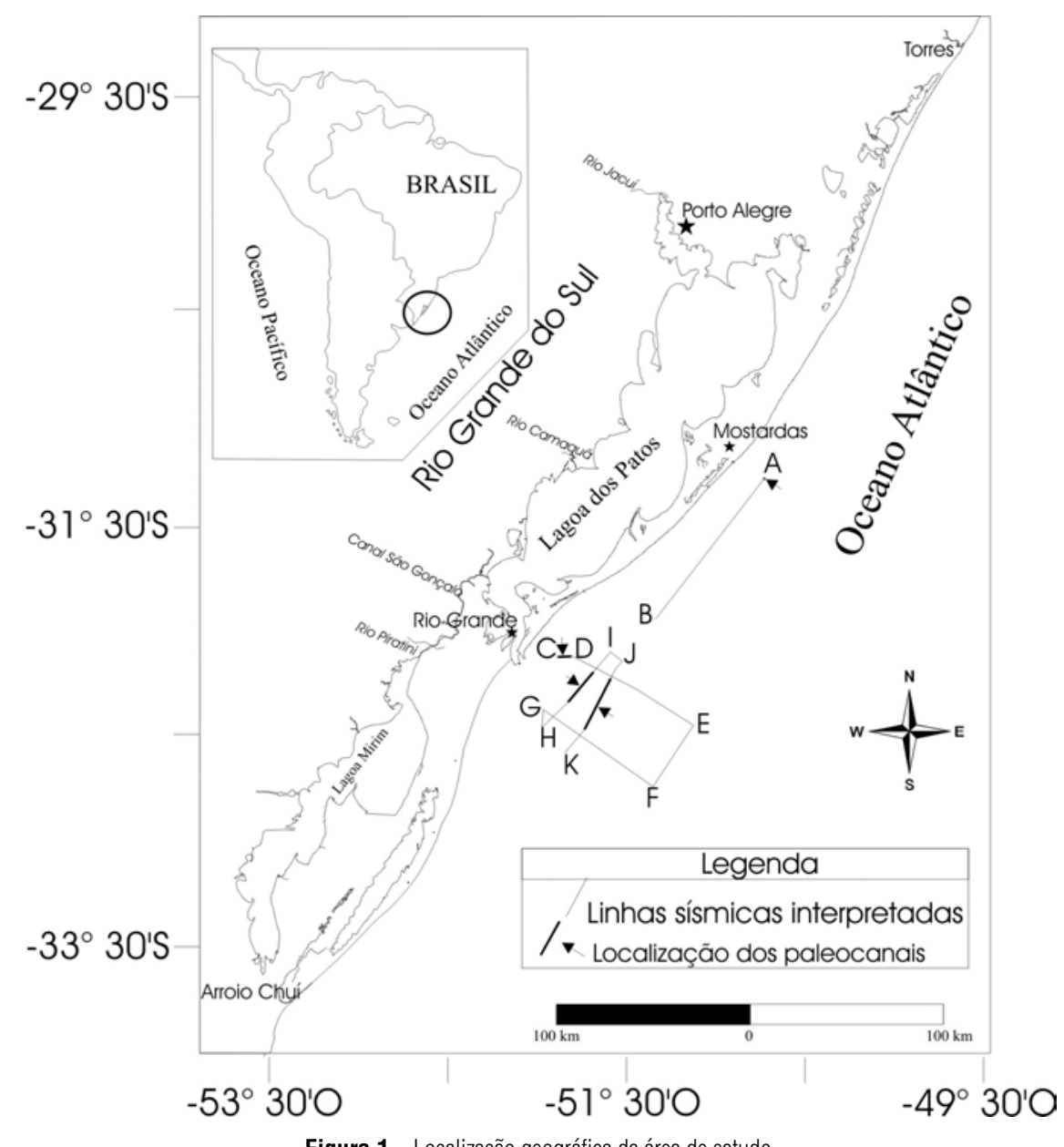

Figura 1 - Localização geográfica da área de estudo.

\section{METODOLOGIA DE AQUISIÇÃO DE DADOS}

0 levantamento sísmico compreendeu duas fases. Na primeira fase foi realizado um perfil paralelo à costa, com início ao largo da cidade de Mostardas $\left(31^{\circ} 12^{\prime} \mathrm{S} ; 50^{\circ} 40^{\prime} 0\right.$ ) e fim nas proximidades da desembocadura da lagoa dos Patos $\left(32^{\circ} 08^{\prime} S ; 51^{\circ} 30^{\prime} 0\right)$. $\mathrm{Na}$ segunda fase foram perfiladas seis linhas sísmicas, sendo quatro paralelas e duas transversais à costa, correspondendo aproximadamente a cerca de 174 milhas náuticas. A figura 1 mostra a disposição das linhas sísmicas na aérea de trabalho.

0 instrumental utilizado para a detecção de estruturas subsuperficiais, constou de um sistema tipo Sparker $($, com fonte sísmica modelo 272-A da EG\&G, de 400 joules de potência, uma unidade registradora EPC 4600 e uma "enguia" de hidrofones composta de 8 elementos e com 15m de comprimento. A escala dos registros sísmicos foi de $250 \mathrm{~ms}$, tendo sido utilizados filtros para freqüências entre 350 e $1.600 \mathrm{~Hz}$. Para o cálculo da profundidade dos refletores foi considerado $1.500 \mathrm{~m} / \mathrm{s}$ como velocidade média de propagação do som na água e no sedimento.

Durante 0 cruzeiro foi realizada a batimetria da área com ecobatímetro marca EDO Depth Recorder Indicator modelo 185, Série 115, de fabricação da EDO Corporation, com freqüência de operação de $12 \mathrm{kHz}$.

As coordenadas foram obtidas através de sistema de rádioposicionamento TRANSIT em intervalos de 10 minutos. 0 planejamento da operação teve como base as cartas náuticas 2.100 e 2.200 da DIRETORIA DE HIDROGRAFIA E NAVEGAÇÃO (DHN/MM) com escalas aproximadas de 1:269.500.

A velocidade média do Navio Oceanográfico Almirante Câmara foi de 6,5 nós durante grande parte do levantamento variando, eventualmente, entre 4,0 e 7,5 nós.

\section{RESULTADOS}

Com a interpretação dos registros sísmicos foi possível observar a disposição subparalela dos refletores internos da plataforma 
continental. As reflexões se destacam pela forte impedância acústica e pela relativamente grande continuidade lateral, em toda a área de trabalho. Com estas características, dois refletores principais puderam ser individualizados em diferentes profundidades de soterramento, ao longo das linhas sísmicas $A B, C D, H I$, $J K$ (Fig. 1). $O$ perfil $A B$ se estende paralelamente a costa, numa direção NE/SO, enquanto que os demais, foram realizados próximo à desembocadura da lagoa dos Patos (Fig. 1).

Os horizontes acústicos registrados foram denominados, neste trabalho, de $R 1 \mathrm{e} R 2$, sendo que o primeiro correspondente à paleosuperfície mais rasa e 0 segundo, a mais profunda.

0 refletor $R 1$ foi registrado entre 10 e 12 metros de profundidade em relação ao fundo submarino e se caracteriza como uma superfície relativamente plana. Apresenta relevo suave na maior parte da área explorada, exibindo apenas algumas irregularidades em locais onde se observam feições acanaladas de menores dimensões (Figs. 2 e 3). Esta reflexão $(R 1)$ pertence a uma seqüência transgressiva que preenche as estruturas em forma de canal que caracterizam o horizonte acústico inferior. Este segundo refletor, também observado nas figuras 2 e 3 , é denominado de $R 2$ e, ao contrário de $R 1$, se apresenta como uma superfície fortemente irregular, redundando numa grande variação nas medidas da sua profundidade. Em relação ao piso submarino, a profundidade de ocorrência de $R 2$ varia entre 14 e 32 metros, sendo que os valores máximos medidos correspondem ao talvegue dos paleocanais. Nos perfis próximos da costa, o refletor $R 2$ se apresenta mais incisivo, observando-se, entretanto, que nas linhas mais distante ocorre uma diminuição na espessura do pacote superior que preenche 0 canal. A profundidade do canal em relação à sua margem é de aproximadamente $8,5 \mathrm{~m}$, medida que igualmente diminui com a distância da costa. Assim como a profundidade, a largura das estruturas também varia. 0 paleocanal observado no perfil $C D$ (Fig.2a) tem uma largura de aproximadamente 2.000 metros. Porém, nas linhas sísmicas $H I$ e $J K$ (Fig. 2b), observa-se 0 alargamento da estrutura para cerca de 3.700 metros. Mais ao largo, o perfil $J K$ (Fig. 3) registra dois canais mais rasos e estreitos, originados provavelmente da bifurcação do canal interpretado nas linhas anteriores.

Caracteristicamente, a assinatura sísmica do pacote sedimentar que tem como topo e base, respectivamente, as reflexões que correspondem ao piso da plataforma e 0 refletor $R 1$, apresenta uma relativa transparência acústica. Reflexões internas à esta unidade sismo-estratigráfica são registradas apenas no interior dos paleocanais, como estruturas de corte e preenchimento.

Em alguns locais é possível observar obstruções nas reflexões internas que surgem como manchas escurecidas no re- gistro, típicas do efeito provocado pela presença de gás no sedimento (Fig. 2b).

Estruturas acanaladas de dimensões menores, dissecando 0 horizonte acústico $R 1$, podem ser observadas com mais freqüência nos registros obtidos nas proximidades da desembocadura da lagoa dos Patos (Figs. 2a, 2b e 3). Estrutura semelhante também foi detectada mais ao norte, na altura da cidade de Mostardas. Este paleocanal, que mede aproximadamente $500 \mathrm{~m}$ de largura, se encontra soterrado a 9,5 metros de profundidade e foi registrado no perfil $A B$, paralelo à costa (Figs. 1 e 4).

\section{DISCUSSÃO}

A cobertura sedimentar e a morfologia da plataforma continental foram fortemente influenciadas pelas oscilações do nível relativo do mar ao longo do tempo geológico. De modo especial, flutuações ocorridas durante o Período Quaternário deixaram evidências, entre as quais se destacam os canais soterrados na plataforma continental, que comprovam a ocorrência de fases de exposição e submersões sucessivas da costa. Na bibliografia internacional, muitos trabalhos podem ser citados entre aqueles que discutem os efeitos provocados pelos eventos transgressivo-regressivos marinhos sobre as margens continentais, desde o Cenozóico até o Recente. A costa leste dos Estados Unidos encontra-se entre aquelas que mais reúnem trabalhos descrevendo estruturas e fácies sedimentares resultantes do retrabalhamento de depósitos antigos durante as variações do nível do mar. Mallinson et al. (1994), identificaram seis seqüências sedimentares na plataforma nordeste da Flórida, a partir do Mioceno, onde detectaram canais soterrados por uma camada de sedimentos de 30 a 40m de espessura. Zi-Qiang et al. (1995) e Boss et al. (2002) registraram estruturas semelhantes na plataforma ao largo da baía de Chesapeake, na Virginia, e na Carolina do Norte. Os canais foram associados pelos autores, a sistemas de drenagens relacionadas ao Período Quaternário. Na costa da Louisiana, Brooks et al. (1995) encontraram estruturas acanaladas, soterradas por até 30 metros de sedimentos, as quais interpretaram como paleocanais que compunha uma rede que drenava terrenos de piemonte em direção à Baia de Chesapeake, a sudeste. Atualmente 0 litoral da Louisiana é formado por um sistema de laguna-barreira, no interior do qual deságuam vários rios, cujos cursos foram interrompidos e modificados pelo desenvolvimento da barreira arenosa no sentido NE/SO (Brooks et al., 1995).

Na plataforma argentina e uruguaia Urien \& Martins (1980) identificaram paleocanais fluviais, classificados como do tipo distributivo, que se estendem até a borda da plataforma e se 


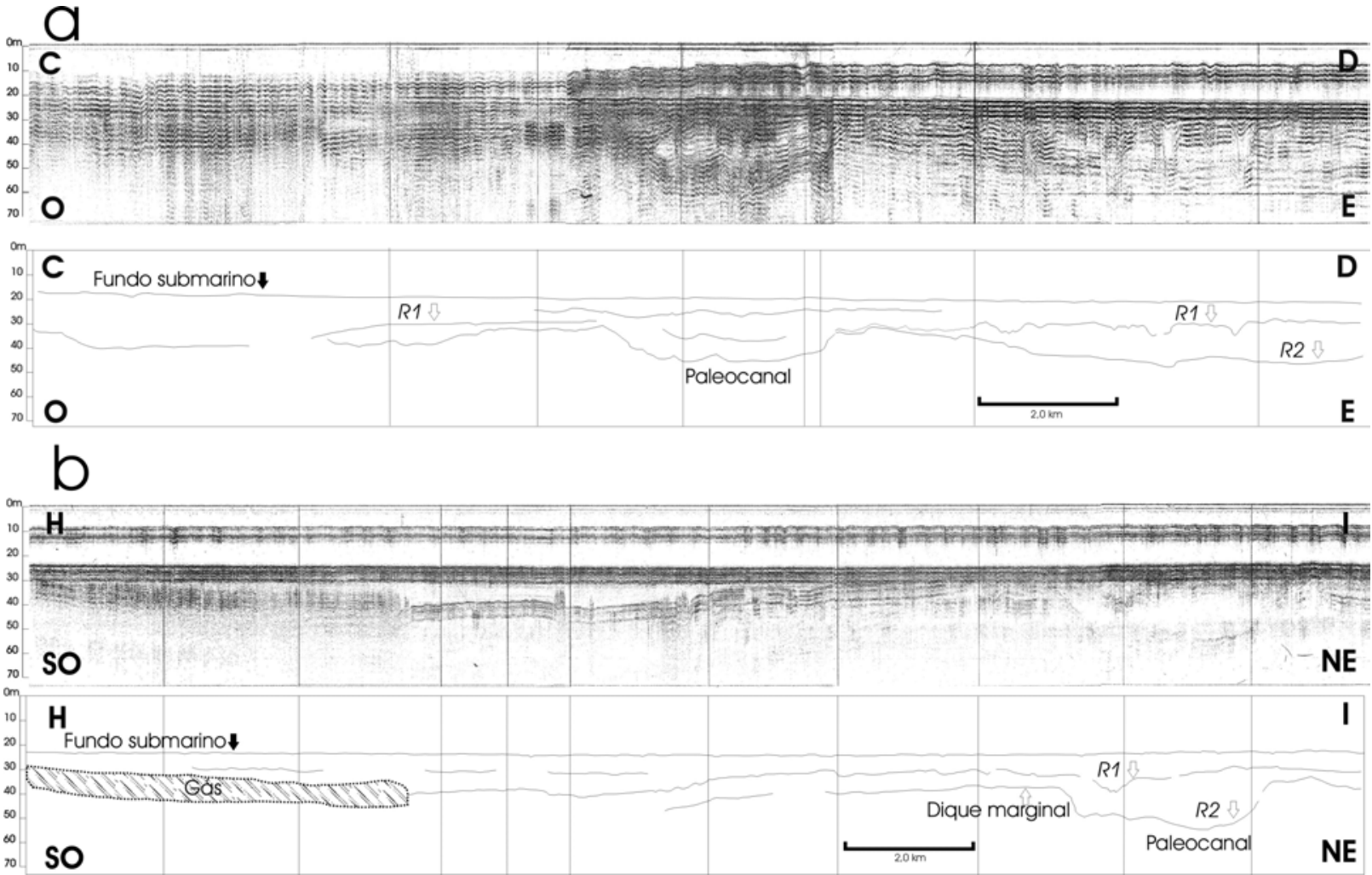

Figura 2 - Registros obtidos durante o levantamento sísmico mostrando os principais refletores identificados e estruturas acanaladas interpretadas como paleocanais na linha $C D$, em cima (3a), e na linha $H I$, em baixo (3b), com a presença de gás.
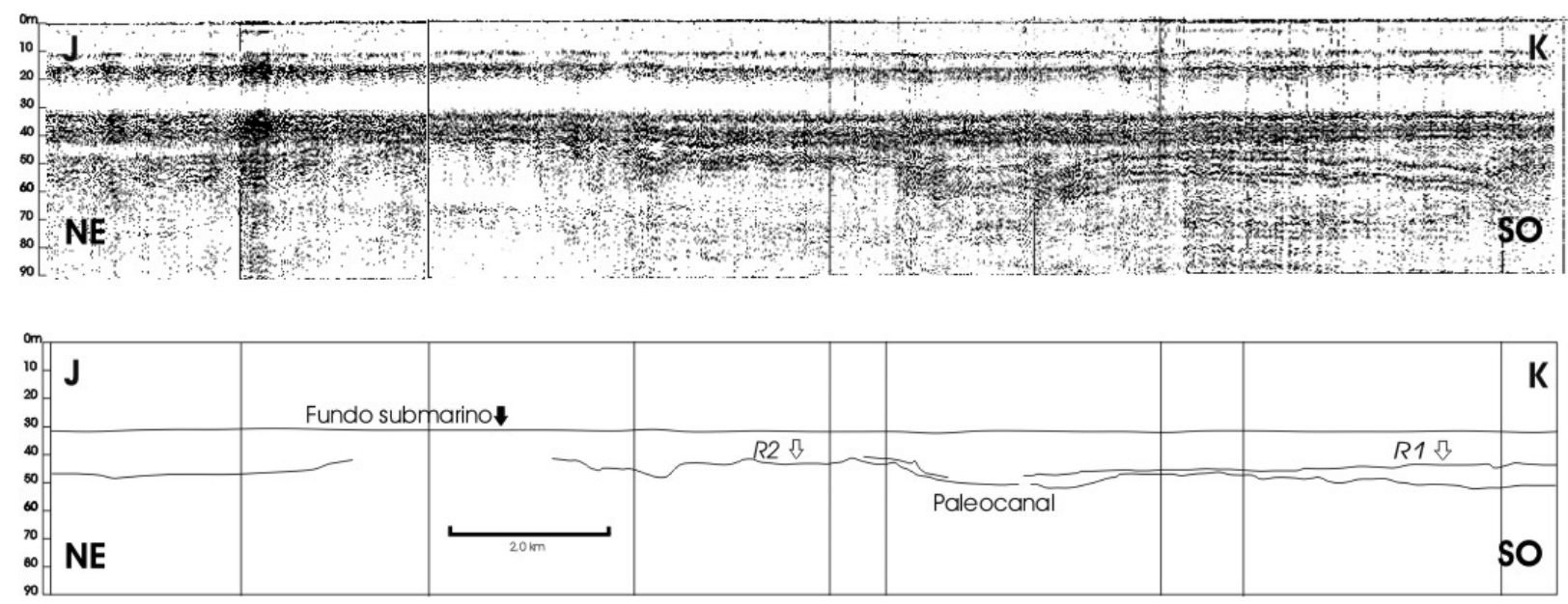

Figura 3 - Perfil sísmico $J K$ mostrando os mesmos sistemas de paleocanais registrados agora na linha mais afastados da costa. As estruturas aparecem mais rasas e com fundo plano demonstrando menor poder de transporte e maior deposição. 

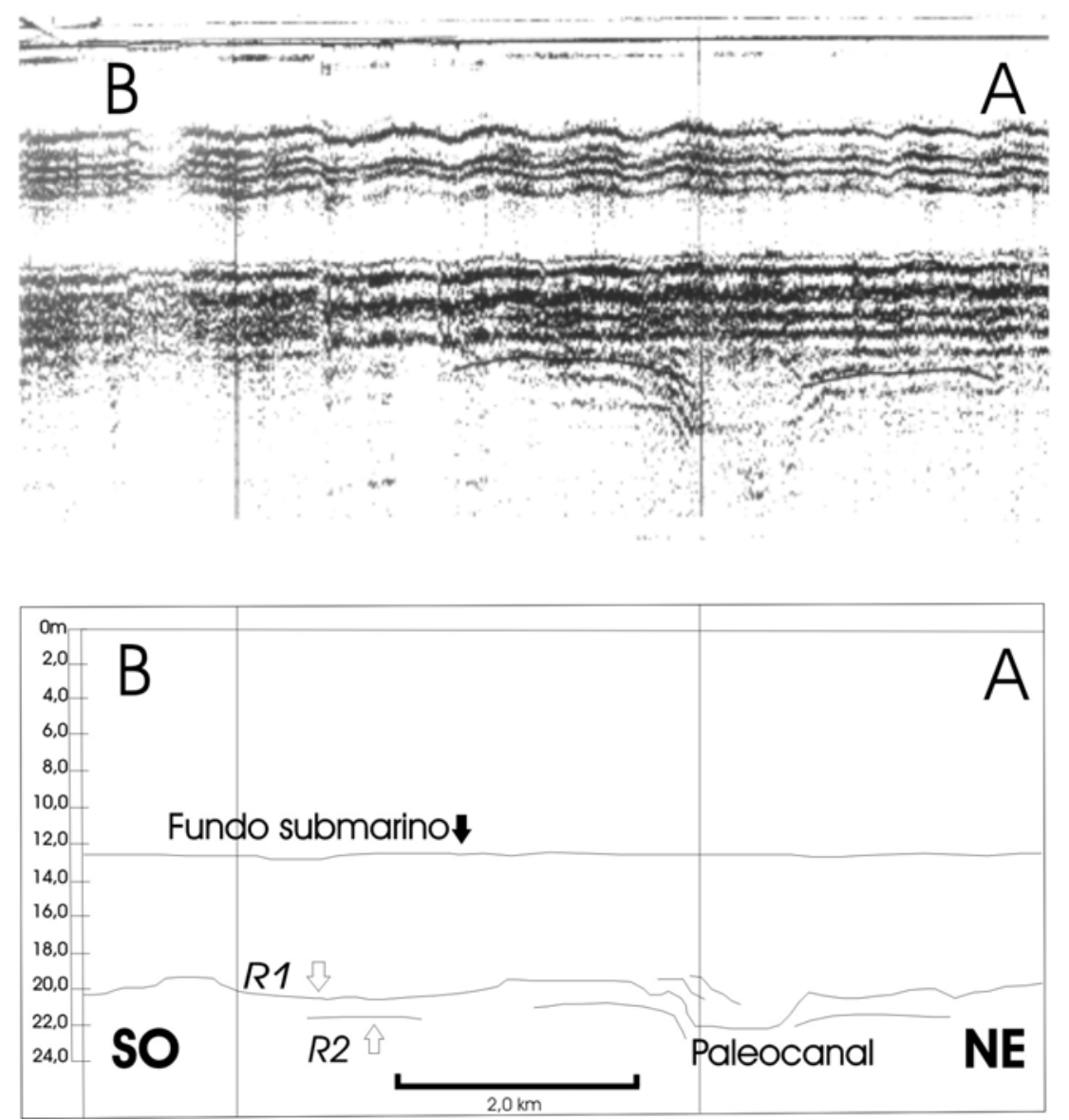

Figura 4 - Paleocanal de menores proporções registrado no perfil sísmico $A B$, obtido mais ao norte, ao largo do município de Mostardas.

conectando, em alguns casos, a canyons no talude continental. Estruturas típicas de paleodrenagem presentes na plataforma continental sul-brasileira foram identificadas por Kowsmann (1975), num trecho da plataforma ao sul da área de estudo. Mais recentemente, Conti \& Furtado (2002) relataram a presença de paleocanais no litoral sul do Estado de São Paulo. Estes autores reconstituíram uma antiga rede de drenagem que foi correlacionada ao rio Ribeira do Iguape, principal sistema fluvial existente atualmente naquela região.

A Província Costeira do Rio Grande do Sul, situada na margem sudoeste do Oceano Atlântico, assemelha-se muito ao litoral leste norte-americano nos aspectos hidrodinâmicos e geomorfológicos. Esta província evoluiu a partir da progradação de sedimentos terrígenos, depositados em sistemas de leques aluviais, retrabalhados nas suas porções distais por, no mínimo, quatro ciclos trans-regressivos sucessivos ocorridos durante os últimos 500 ka. AP. (Villwock, 1984; Villwock \& Tomazelli,
1995). A última regressão pleistocênica (Zembruscki, 1979) expôs subaéreamente a quase totalidade da plataforma continental durante 0 Último Máximo Glacial, quando o nível do mar situava-se aproximadamente na atual cota batimétrica de $135 \mathrm{~m}$ (Kowsmann et al., 1977). Estabeleceu-se aí um panorama deposicional resultando no desenvolvimento de uma extensa planície costeira com transporte de sedimentos terrígenos através das redes de drenagem até a plataforma continental (Kowsmann et al., 1977; Corrêa \& Ade, 1987). A transgressão holocênica, que atingiu 0 seu máximo há 5ka AP. (Corrêa \& Toldo Jr., 2002), afogou as desembocaduras fluviais e a planície costeira, recobrindoa por um "lençol de areias transgressivas" (Kowsmann et al., 1977). A formação de uma barreira arenosa holocênica, integrante de um sistema complexo de múltiplas barreiras que reúne ainda as lagoas dos Patos e Mirim, foi episódio final conseqüente das variações do nível do mar que afetaram este setor costeiro (Villwock \& Tomazelli, 1995; Tomazelli et al., 2000). A partir de 
então, ficaram retidos no interior deste sistema lagunar toda a drenagem continental que anteriormente atingia a quebra da plataforma continental. As desembocaduras dos estuários e os canais fluviais foram igualmente soterrados pelas areias transgressivas. Desta forma, o registro dos canais soterrados representa evidências da drenagem pleistocênica sobre a antiga planície costeira, na atual plataforma continental.

Analisando modelos deposicionais na plataforma continental do Rio Grande do Sul, Uruguai e Argentina, Urien \& Martins (1980) ressaltam que os atuais complexos fluviais do Guaíba, Camaquã, São Lourenço e Piratini, no Brasil e Prata e Salado no Uruguai, possuem extensões de seus caudais sobre a plataforma continental.

A mineralogia pode fornecer elementos para confirmar a existência destas redes de drenagem pleistocênicas. Corrêa \& Ade (1987) relacionaram as assembléias de minerais pesados na plataforma interna com as áreas fonte do complexo ígneometamórfico do Escudo Sul-riograndense. Os autores verificaram, nos sedimentos da plataforma, a presença de minerais provenientes do interior continental, transportados por sistemas fluviais que atualmente não alcançam mais 0 ambiente marinho. Utilizando também aspectos mineralógicos e texturais do sedimento através da razão quartzo/feldspato, Calliari \& Abreu (1984) encontraram semelhanças entre uma amostra da plataforma com sedimentos coletados do rio Piratini, que atualmente desemboca no Canal São Gonçalo, no interior da planície costeira. De acordo com o mapa da morfologia do Quaternário de Martins et al. (1996), no pleistoceno este sistema fluvial alcançava a plataforma continental próximo do local onde os registros da Operação Geocosta Sul II foram obtidos. Calliari \& Abreu (1984) classificaram o sedimento desta amostra como areia muito grossa a grossa, constituída de grãos angulosos e oxidados, sugerindo a existência de um depósito fluvial pretérito associado a canais afogados. 0 afloramento deste depósito, na superfície da plataforma continental, poderia ser explicado através do conceito da canibalização do substrato pleistocênico pela dinâmica atual, como descrevem Kowsmann et al. (1977). Análise realizada posteriormente, classificou melhor este depósito confirmando-0 como de origem terrígena, constituído de areias relíquias, subarcosianas ( $F / F+Q z=0,12)$ (Calliari \& Fachin, 1993). Calliari et al. (1994) também verificaram, mais tarde, que a área de abrangência destes sedimentos relíctos é mais ampla e descontínua do que 0 imaginado inicialmente. Com isso, autores cogitaram a possibilidade da existência de vários canais soterrados nas proximidades do parcel do Carpinteiro.

A ocorrência de paleocanais, como os descritos neste traba-
Iho, já foi citada anteriormente para a plataforma continental do Rio Grande do Sul (Kowsmann et al., 1977) e sob a barreira arenosa do sistema lagunar Patos-Mirim. Estes últimos são indícios das antigas conexões entre as lagunas e 0 ambiente marinho adjacente. Toldo Jr. et al. (1991) cogitaram a possibilidade da região conhecida como Barra Falsa, situada a $87 \mathrm{~km}$ ao norte da atual desembocadura, ter sido um canal de ligação entre a laguna dos Patos e 0 oceano. Para o sul, Ayup-Zouain et al. (2003) observaram, através de análise digital em imagens de satélite, uma feição morfológica, na região do banhado do Taim, a qual presumivelmente, seria a ligação entre a laguna Mirim com o mar, antes da Época Holocenica. Por outro lado, com base na interpretação de um perfil sísmico realizado no canal de acesso ao porto de Rio Grande, na atual desembocadura da lagoa dos Patos, Corrêa et al. (2003) observaram, em subsuperfície, estruturas de barreira cruzando transversalmente o canal, de onde concluíram que a conexão com o mar não ocorria anteriormente neste local.

De qualquer forma, a relação dos paleocanais da plataforma, observados nas figuras 2a, $2 b, 3$ e 4, deste trabalho, com paleocanais que se presume existirem no interior do sistema lagunar, ainda não foi determinada. Somente com a realização de novas campanhas de aquisição de dados, será possível estabelecer a relação desta antiga rede de drenagem com os atuais sistemas fluviais que deságuam no interior da atual laguna dos Patos.

\section{CONCLUSÃO}

A estrutura subsuperficial rasa da plataforma continental do Rio Grande do Sul, como toda a plataforma continental Sul-brasileira, teve sua evolução fortemente condicionada às flutuações do nível do mar, ocorridas especialmente no Período Quaternário. Estágios alternados de exposição e de submersão resultaram no retrabalhamento dos sedimentos e no desenvolvimento de ambientes deposicionais de acordo com as condições ambientais instaladas. Durante o período de exposição se formou uma extensa planície costeira com formação de redes de drenagem fluvial e sistemas laguna-barreira paralela à costa. A transgressão holocênica subseqüente, retrabalhou estes depósitos e afogou as desembocaduras fluviais, resultando em um novo modelado costeiro que permaneceu relativamente preservado até 0 tempo presente.

Nos registros aqui descritos, o horizonte acústico $R 1$ representa a base de uma seqüência transgressiva que preenche estruturas erosivas, em forma de canais, escavadas sobre a paleosuperficie demarcada pelo refletor $R 2$. Este, por sua vez, corresponde ao topo de uma seqüência sismo-estratigráfica, provavelmente de idade pleistocênica, sobre a qual se instalou a paleodre- 


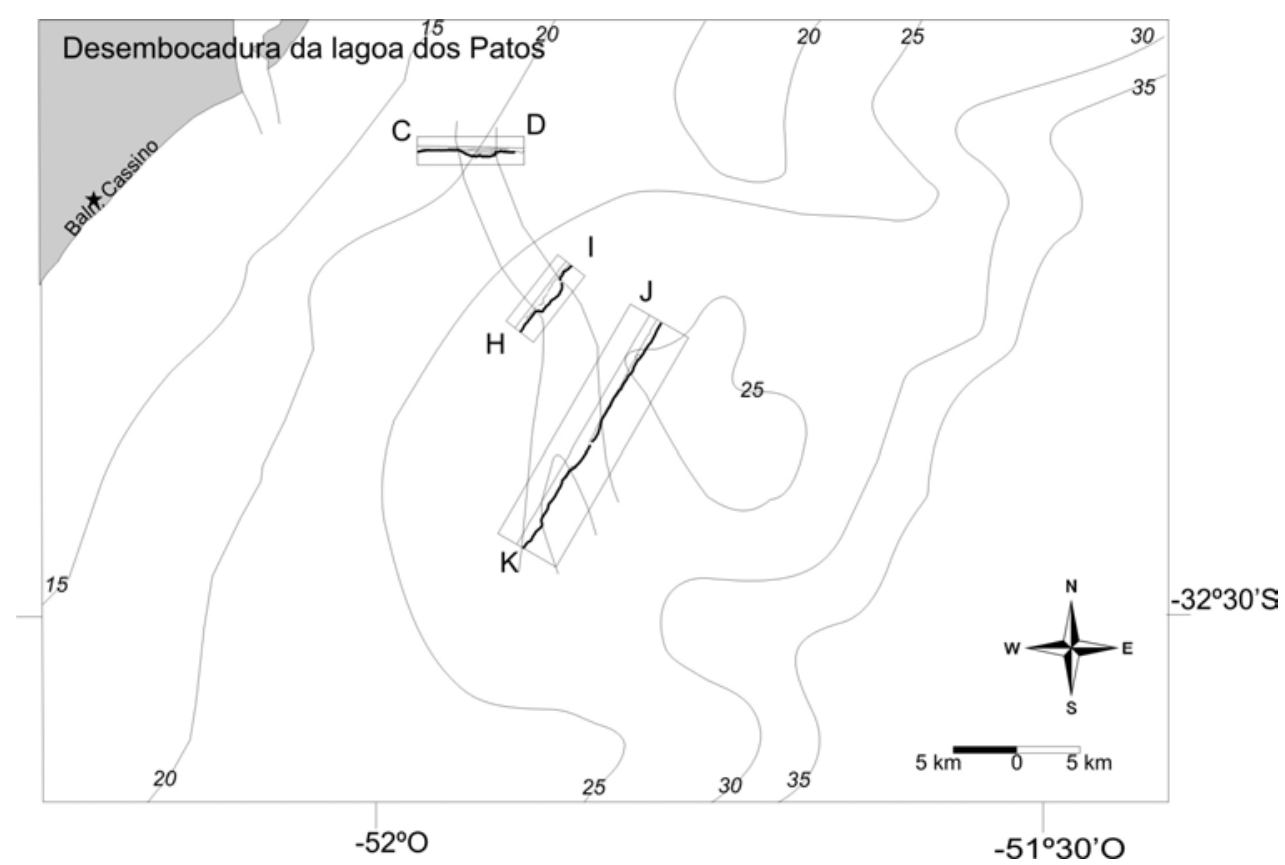

Figura 5 - Sistema de paleodrenagem existente na plataforma continental interna do Estado do Rio Grande do Sul, reconstituído da interpretação dos perfis sísmicos obtidos durante a Operação Geocosta Sul II.

nagem. As estruturas mapeadas constituem as evidências desta drenagem pretérita atualmente soterrada pelo prisma sedimentar da plataforma.

A análise em conjunto dos perfis sísmicos obtidos possibilitou definir como a direção N/NE-SE/SO como orientação predominante destes paleocanais (Fig. 5). Os canais soterrados são relativamente profundos e de largura expressiva, alcançando até $3.700 \mathrm{~m}$. Conforme aumenta a distância da costa, a profundidade do talvegue diminui e 0 fundo torna-se gradativamente mais plano, indicando redução da capacidade de transporte e deposição no interior do canal.

0 sistema apresenta subambientes associados, típicos de ambiente fluvial, tais como dique marginal e planície de inundação. Estes subambientes podem ser identificados pelo aprofundamento da paleosuperfície $R 2$ a partir da margem, topograficamente mais elevada. Nas porções mais baixas desta planície ocorre a presença de gás, reconhecido no perfil sísmico $H I$.

Os canais menores que dissecam o refletor $R 1$ visto nas linhas sísmicas próximas à barra da lagoa dos Patos, bem como o canal registrado mais ao norte, ao largo de Mostardas, compõe um sistema de drenagem de segunda ordem. Estes, provavelmente teriam se desenvolvido durante o Holoceno, num período de tempo em que o nível do mar esteve abaixo do atual.
Pelos trabalhos até o momento publicados não é possível associar os paleocanais registrados na operação Geocosta Sul II com sistemas fluviais que atualmente desembocam no interior laguna dos Patos. Entretanto, algumas hipóteses podem ser levantadas procurando se estabelecer alguma continuidade com estes ambientes continentais. Levando-se em consideração o mapa morfológico do Quaternário, proposto por Martins et al. (1996), a localização do antigo leito do rio Piratini coincide, aproximadamente, com a posição das estruturas mapeadas na plataforma atual. A esse fato, soma-se o resultado da análise mineralógica e textural realizada Calliari \& Abreu (1984) e Calliari et al. (1994) em uma amostra superficial coletada na área onde os paleocanais foram registrados. Por outro lado, a presença de estrutura de barreira, interpretada no registro obtido por Corrêa et al. (2003) no canal da lagoa dos Patos, pode tornar improvável a possibilidade dos canais se relacionarem ao rio Piratini.

Observando a orientação N/NE-SE/SO, apresentada pelo sistema de paleocanais registrados, outra hipótese pode ser discutida. Esta direção é a mesma que apresentam os atuais sistemas fluviais, sendo o rio Camaquã, responsável atualmente pela formação de um delta intra-lagunar, o que se localiza mais próximo desta região. 0 fato sugere o rio Camaquã como, provavelmente, o responsável pela formação dos paleocanais mapeados. 
0 mesmo aspecto, orientação das drenagens continentais, correlaciona o paleocanal registrado ao norte da desembocadura da laguna com o moderno rio Jacuí. Este rio deságua no extremo norte na lagoa dos Patos e o prolongamento inferido do seu leito tende para a estrutura registrada ao largo da cidade de Mostardas, situada na costa oceânica do sistema laguna-barreira.

Após os dados apresentados, torna-se fundamental a realização de novos levantamentos sísmicos na plataforma continental e no interior do sistema lagunar Patos-Mirim, visando inserir os paleocanais descritos neste trabalho no contexto evolutivo da costa. Datações e análises palinológicas de material coletado através de testemunhagem na barreira arenosa, também devem acrescentar informações importantes situando, temporalmente, os eventos que terminaram por construir a província costeira do Estado do Rio Grande do Sul.

\section{AGRADECIMENTOS}

Agradecemos a Diretoria de Hidrografia e Navegação (DHN) pela seção do Navio Hidrográfico Almte. Câmara que tornou possível a realização da Operação Geocosta Sul II.

0 Conselho Nacional de Desenvolvimento Científico e Tecnológico (CNPq) que disponibilizou recursos de infra-estrutura necessária em termos de pessoal, material e equipamentos para realização da Comissão Oceanográfica.

\section{REFERÊNCIAS}

AYUP-ZOUAIN RN, FERREIRA HP, BARBOZA EG \& TOMAZELLI LJ. 2003. Evidência morfológica de um paleocanal holocênico da laguna Mirim nas adjacências do banhado Taim. Anais IX ABEQUA p. 82, Recife, PE, Brasil.

BOSS SK, HOFFMAN CW \& COOPER B. 2002. Influence of fluvial processes on the Quaternary geologic framework of the continental shelf, North Caroline, USA. Mar. Geol. 183: 45-65.

BROOKS GR, KINDINGER JL, PENLAND S, WILLIANS SJ \& MCBRIDE RA. 1995. East Louisiana continental shelf sediments: A product of delta reworking. J. Coast. Res. 11(4): 1026-1036. Fort Lauderdale, Florida. USA. CERF.

CALLIARI LJ. 1984. Operação Geocosta Sul II. Relatório Técnico. Primeira Etapa. Noc. Alte. Câmara. 07 -10/04/1984. Convênio FURGCIRM. LOG/DEGEO/FURG.

CALLIARI LJ \& ABREU JGN. 1984. Litologia da Plataforma continental interna adjacente à cidade do Rio Grande, RS através da Interpretação de registros de sonar de varredura lateral e amostragem superficial. Congr. Bras. Geol., Anais, XXXIII 4: 1553-1564, Rio de Janeiro, RJ.

CALLIARI LJ \& FACHIN S. 1993. Laguna dos Patos. Influência nos depósitos lamíticos costeiros. Pesquisas, 20(1): 57-69, Instituto de
Geociências, UFRGS. Porto Alegre, RS, Brasil.

CALLIARI LJ, ESTEVES LS, OLIVEIRA CPL, TOZZI HAM, PEREIRA DA SILVA R \& CARDOSO JN. 1994. Padrões sonográficos de um afloramento de beachrocks na plataforma interna do Rio Grande do Sul (COMEMIR/OSNLR). Notas Técnicas 7: 27-32. CO/IG/UFRGS. Porto Alegre, RS, Brasil.

CONTI LA \& FURTADO WV. 2002. The paleovalleys in Southeastern Brazilian Continental Shelf: Could they be older than thought. Abstracts, $2^{\text {nd }}$ Conference of the International Geological Correlation Program, Project n464, 19-20, São Paulo and Cananeia Cities, SP, Brazil.

CORRÊA ICS. 1982. Estudo da sedimentação quaternária da plataforma continental média e externa do Rio Grande do Sul. Anais XXXII Congr. Bras. Geol., 4: 1504-1513, Salvador, BA. SBG.

CORRÊA ICS \& ABREU VS. 1984. Evolução da sedimentação holocênica da plataforma continental e talude superior entre Rio Grande e Torres, RS. Anais XXXIII Congr. Bras. Geol. 63-70, Rio de Janeiro, RJ. SBG.

CORRÊA ICS \& ADE AB. 1987. Contribuição ao estudo da paleogeografia da plataforma continental do Rio Grande do Sul. Anais I ABEQUA 1: 37-48, Porto Alegre, RS, Brasil.

CORRÊA ICS, MARTINS LRS, KETZER JMM, ELIAS ARG \& MARTINS R. 1996. Evolução sedimentológica e paleogeográfica na plataforma continental sul e sudeste do Brasil. Notas Técnicas, 9: 51-61. CECO/G/UFRGS.

CORRÊAA ICS \& TOLDO Jr. EE. 2002. Sea-level history since Last Glacial Maximum infered from continental shelf morphology of southern Brazil. Abstracts, $2^{\text {nd }}$ Conference of the International Geological Correlation Program, Project n464, 21-23, São Paulo and Cananéia Cities, Brazil.

CORRÊA ICS, ALIOTTA S \& WESCHENFELDER J. 2003. Evidências de estruturas de barreira no canal de acesso à laguna dos Patos. Anais IX ABEQUA p. 122. Recife, PE, Brasil.

FIGUEIREDO Jr. AG. 1975. Geologia dos depósitos calcários biodetríticos da plataforma continental do Rio Grande do Sul. Dissertação (Mestrado). Universidade Federal do Rio Grande do Sul, Porto Alegre, RS.

FIGUEIREDO Jr. AG \& KOWSMANN RO. 1976. Interpretação dos registros de sonar de varredura lateral obtidos na plataforma Sul-riograndense durante a Operação Geomar VII. Rio Janeiro, PETROBRAS, DNPM, CPRM, DHN, CNPq. PROJETO REMAC. Relatório Interno. CPRM.

FIGUEIREDO Jr. AG. 1980. Response of water column to strong wind forcing Southern Brazilian inner shelf: implication for sand ridge formation. Mar. Geol., 35: 367-376.

KOWSMANN RO. 1973. Mapa preliminar de fácies entre Chuí e Santos. Rio de Janeiro. CPRM, DIGEON, REMAC.

KOWSMANN RO. 1975. Relatório de bordo. In DG-32-VI. Diretoria de Hidrografia e Navegação, LIV Comissão Oceanogrática. Operação Geomar VI. Noc. Almte. Saldanha (27/03 a 30/04/1975), p. 4-56. 
KOWSMANN RO, COSTA MPA, VICALVI MA, COUTINHO MGM \& GAMBÔA LAP. 1977. Modelo da sedimentação holocênica na plataforma continental sul brasileira. In Projeto REMAC - Evolução sedimentar holocênica da plataforma continental e do talude do Sul do Brasil. Série Projeto REMAC, 2: 7-26. Rio de Janeiro, PETROBRAS, CENPES, DINTEP.

MALLINSON DJ, COMPTON JS, SNYDER SW \& HODELL DA. 1994. Strontium isotopes and Miocene sequence stratigraphy across the Northeast Florida plataform. J. Sediment. Res. (B. Stratigr Global Stud. SEPM. B64(3): 392-407.

MARTINS LR, VILLWOCK JA \& MARTINS IR. 1972. Estudo preliminar sobre a distribuição faciológica da plataforma Continental Brasileira. Pesquisas, (1): 51-56, Porto Alegre. CECO/IG/UFGRS

MARTINS LR, URIEN CM, CORREAA ICS \& MARTINS IR. 1996. Late Quaternary processes along the Rio Grande do Sul continental shelf (Southern Brazil). Notas Técnicas. (9): 62-68. CEC0/IG/UFRGS.

TOLDO Jr. EE, AYUP-ZOUAIN RN, CORRÊA ICS \& DILLEMBURG SR. 1991. Barra Falsa: Hipótese de um paleocanal holocênico de comunicação entre a laguna dos Patos e o oceano Atlântico. Pesquisas 18(2): 99-103. CECO/IG/UFRGS.

TOMAZELLI LJ, DILLEMBURG SR \& VILLWOCK JA. 2000. Late Quaternary geological history of Rio Grande do Sul coastal plain, Southern Brazil. Revista Brasileira de Geociências, 30(3): 470-472.
URIEN CM \& MARTINS LR. 1980. Evolução geológica do quaternário do litoral Atlântico Uruguaio, plataforma continental e regiões vizinhas. Notas Técnicas, 3: 7-43. CECO/IG/UFRGS. Porto Alegre, RS.

VILLWOCK JA. 1984. Geology of the coastal province of the Rio Grande do Sul, Southern Brazil. A Synthesis. Pesquisas 16: 5-49. CECO/IG/UFRGS

VILLWOCK JA, TOMAZELLI LJ, LOSS EL, DEHNHARDT EA, HORN NO, BACHI FA \& DEHNHARDT BA. 1986. Geology of the Rio Grande do Sul coastal plain. In: Rabassa, J. (Ed) Quaternary of South America and Antartic Peninsula. A.A. Balkema, Rotterdam. 4: 79-97.

VILLWOCK JA \& TOMAZELLI LJ. 1995. Geologia costeira do Rio Grande do Sul. Notas Técnicas, 8: 1-45. CECO/IG/UFGRS.

ZEMBRUSCKY SG. 1979. Geomorfologia da margem continental sul brasileira e das bacias oceânicas adjacentes. In (Chaves, H.A.F. Ed). Geomorfologia da Margem Continental Brasileira e das Áreas Oceânicas Adjacentes. Série Projeto REMAC, 7: 129-177. PETROBRAS, DNPM, CPRM, DHN, CNPq.

ZI-QIANG C, HOBBS CH, WEHMILLER JF \& KIMBALL SM. 1995. Late quaternary paleochennel system on the continental shelf, South of the Chesapeake Bay entrance. J. Coast. Res. 11(3): 605-614. Fort Lauderdale, Florida.

\section{NOTAS SOBRE OS AUTORES}

José Gustavo Natorf de Abreu é graduado em Oceanologia (FURG/1984), especialista em Geologia e Geofísica Marinha (LAGEMAR-UFF/1994), Mestre em Geologia Marinha (LAGEMAR-UFF/1998). Desde 1995 é responsável pelas Disciplinas de Morfologia do Fundo Oceânico e Sedimentação Marinha do Curso de Graduação em Oceanografia da Universidade do Vale do Itajaí (UNIVALI/SC). Organizou e coordenou os cruzeiros oceanográficos Geocosta Sul-SC-001 e 002 em 1996 e 1997 respectivamente. Tem como principais linhas de pesquisa a geomorfologia, sedimentologia e geofísica em ambientes marinhos e a exploração de recursos minerais do mar.

Lauro Júlio Calliari é oceanógrafo (FURG/1975). Mestre em Geologia Marinha (IG/UFRGS-1980) e Doutor em Ciências Marinhas pelo Virginia Institute of Marine Science (VA, USA-1990). Atualmente é professor titular da Fundação Universidade Federal do Rio Grande (FURG) onde leciona as disciplinas de Morfodinâmica Costeira, Oceanografia Geológica e Recursos Minerais do Mar nos programas de graduação e pós-graduação. Participou e coordenou vários cruzeiros oceanográficos a bordo de navios da Marinha do Brasil (Operações Geomar e Geocosta) no âmbito do Programa de Geologia e Geofísica Marinha. Seu interesse em pesquisa envolve processos costeiros e recursos minerais do mar. 